\title{
Myocardial ischemia is more important than the effects of cardiopulmonary bypass on myocardial water handling and postoperative dysfunction: A pediatric animal model
}

\author{
Jonathan R. Egan, MBBS, ${ }^{a, b}$ Tanya L. Butler, PhD, ${ }^{a, b}$ Andrew D. Cole, BAppSc, ${ }^{a}$ Avetis Aharonyan, MD, ${ }^{a}$ \\ David Baines, MBBS, ${ }^{a, b}$ Neil Street, MBBS, ${ }^{a}$ Manchula Navaratnam, MBchB, ${ }^{a}$ Oliver Biecker, MEng, ${ }^{a}$ \\ Carla Zazulak, BSc, ${ }^{a}$ Carol G. Au, BSc, ${ }^{a, b}$ Yee Mun Tan, BSc, ${ }^{a}$ Kathryn N. North, MD, ${ }^{b}$ and David S. Winlaw, MD ${ }^{a, b}$
}

From the Kids Heart Research, ${ }^{\mathrm{a}}$ The Children's Hospital at Westmead, Sydney, Australia, and the Discipline of Pediatrics and Child Health, ${ }^{\text {b }}$ Faculty of Medicine, University of Sydney, Australia.

JRE was supported by a National Health and Medical Research Council (NHMRC) Biomedical Research Scholarship (297113), CGA is supported by an NHMRC Dora Lush Scholarship (358800), and DSW is a National Heart Foundation of Australia Career Development Fellow. This work was supported by a NHMRC Project Grant (402710).

Received for publication Jan 3, 2008; revisions received March 11, 2008; accepted for publication April 6, 2008.

Address for reprints: David S. Winlaw, MD, FRACS, Paediatric Cardiac Surgeon, Kids Heart Research, Locked Bag 4001, Westmead NSW 2145, Australia (E-mail: davidw@ chw.edu.au).

J Thorac Cardiovasc Surg 2008;136:126573

\section{2-5223/\$34.00}

Copyright $\odot 2008$ by The American Association for Thoracic Surgery

doi:10.1016/j.jtcvs.2008.04.002
Objectives: Low cardiac output state is the principal cause of morbidity after surgical intervention for congenital heart disease. Myocardial ischemia-reperfusion injury, apoptosis, capillary leak syndrome, and myocardial edema are associated factors. We established a clinically relevant model to examine relationships between myocardial ischemia, edema, and cardiac dysfunction and to assess the role of the water transport proteins aquaporins.

Methods: Sixteen lambs were studied. Seven were control animals not undergoing cardiopulmonary bypass, and 9 underwent bypass. Six had 90 minutes of aortic crossclamping with blood cardioplegia and moderate hypothermia. The remaining 3 underwent cardiopulmonary bypass without aortic crossclamping. Hemodynamic and biochemical data were recorded, and myocardial edema, apoptotic markers, and aquaporin expression were determined after death.

Results: The group undergoing cardiopulmonary bypass with aortic crossclamping had a low cardiac output state, with early postoperative tachycardia, hypotension, increased serum lactate levels, and impaired tissue oxygen delivery $(P<.05)$ compared with the group undergoing cardiopulmonary bypass without aortic crossclamping. The lambs undergoing cardiopulmonary bypass with aortic crossclamping had increased myocardial water $(P<.05)$ compared with those not undergoing cardiopulmonary bypass and a 2 -fold increase in aquaporin 1 mRNA expression $(P<.05)$ compared with those not undergoing cardiopulmonary bypass and those undergoing cardiopulmonary bypass without aortic crossclamping.

Conclusions: A temporal association between hemodynamic dysfunction, myocardial edema, and increased aquaporin 1 expression was demonstrated. Cardiopulmonary bypass without ischemia was associated with minimal edema, negligible myocardial dysfunction, and static aquaporin expression. Ischemic reperfusion injury is the main cause of myocardial edema and myocardial dysfunction, but a causal relationship between edema and dysfunction remains to be proved.

$\mathrm{L}$ ow cardiac output state (LCOS) is the most important cause of morbidity and mortality after infant cardiac surgery. ${ }^{1}$ LCOS is caused by contractile failure coupled with compensatory increases in circulatory afterload. ${ }^{2}$ Clinically, LCOS is apparent as reduced perfusion pressure, increased heart rate, reduced oxygen delivery, and increased inotropy. ${ }^{1}$ With time, LCOS resolves, but its legacy is apparent as renal and sometimes neurologic impairment. Overall outcomes after infant cardiac surgery are excellent, but patients with high-risk lesions, such as hypoplastic left heart syndrome, and those undergoing major reconstructions still experience mortality and important morbidity as a result of LCOS. ${ }^{3}$ Improvements in supportive practices 

Abbreviations and Acronyms
$\mathrm{AQP}=$ aquaporin
$\mathrm{AXC}=$ aortic crossclamping
$\mathrm{COP}=$ colloid osmotic pressure
$\mathrm{CPB}=$ cardiopulmonary bypass
$\mathrm{I} / \mathrm{R}=$ ischemia and reperfusion
LCOS = low cardiac output state
TUNEL $=$ TdT-mediated dUTP nick-end labeling

have reduced LCOS, ${ }^{1}$ but minimal progress has been made in understanding the underlying causes, and standard pediatric myocardial protection strategies have remained static for 15 years.

LCOS occurs early, during the first 6 to 12 hours postoperatively, and is temporally associated with increased total body water content and generalized tissue edema. ${ }^{4,5}$ Capillary leak syndrome and myocardial edema have a similar time course after pediatric cardiac surgery and appear integral to LCOS, with many clinicians asserting a causal relationship., Studies of cardiac ultrastructure have demonstrated myocellular and mitochondrial edema after ischemia and reperfusion (I/ R). ${ }^{7}$ Increased myocardial water content has been associated with myocardial dysfunction, both systolic ${ }^{8}$ and diastolic. ${ }^{9}$ Small increases in myocardial water (increase of 3\%) have been shown by Laine and Allen, ${ }^{10}$ in an animal model, to significantly affect myocardial function (decrease of 30\%).

Myocardial edema can develop through a combination of vasogenic and cytotoxic pathways. Typically, interstitial or vasogenic edema is described ${ }^{11,12}$ and associated with increased capillary leak. Intracellular or cytotoxic edema also occurs $^{13,14}$ as a result of the osmotic effect of lactate accumulated by the myocyte during anaerobic metabolism. Existing antiinflammatory therapies, such as corticosteroids and aprotinin, that seek to target the systemic inflammatory response syndrome do not prevent the extravasation of water, ${ }^{6,12,15}$ leading us to investigate other possible avenues of intervention, such as the role of water channels or aquaporins (AQPs). ${ }^{15}$

AQPs are a family of 13 proteins that form transmembrane channels permitting rapid movement of water along osmotic gradients. We and others have demonstrated that AQP1 is the main myocardial AQP that exists within the endothelium and cardiomyocyte plasma membranes. ${ }^{14,16,17}$ In human hearts other AQPs have been demonstrated only at a transcript level. ${ }^{14}$ AQPs in the brain have been shown to be important in animal models after ischemic stroke and water intoxication; for example, AQP4 knockout mice have significantly less cerebral edema and improved function compared with that seen in wild-type mice after these insults. ${ }^{18}$ Given some of the pathophysiologic similarities, it is conceivable that AQPs within the heart could also be involved in the development or resolution of myocardial edema and LCOS.
A role for AQPs in myocardial water handling has been shown in osmotically challenged isolated cardiomyocytes, ${ }^{19}$ and myocardial AQPs have been increasingly studied in relevant models, ${ }^{17,20,21}$ including our work with isolated cardiomyocytes and isolated heart preparations in response to I/R and hypo-osmotic stress. ${ }^{17}$ These studies demonstrated a physiologic role but no apparent change in AQP expression during the short time frame possible with these in vitro experiments. ${ }^{17}$ Furthermore, the role of cardiopulmonary bypass (CPB) in water handling is difficult to reproduce in vitro. Consequently, we have produced a clinically accurate model of infant LOCS to assess changes in myocardial AQP expression in this setting.

Induction of apoptotic pathways has been suggested as a mechanism of cell loss contributing to LCOS and later ventricular dysfunction in the pediatric setting. ${ }^{22}$ Using the same model, we sought to evaluate the extent to which apoptosis was evident in control hearts, as well those undergoing $\mathrm{CPB}$ with or without aortic crossclamping (AXC).

\section{Materials and Methods}

The Animal Ethics Committee at The Children's Hospital at Westmead approved this study, and all animals received humane care in compliance with National Health and Medical Research Council animal care guidelines.

\section{Study Design}

Sixteen lambs of either sex weighing $7.4 \pm 0.4 \mathrm{~kg}$ were used.

Non-CPB control animals. There were 7 control animals that underwent cardiectomy without receiving CPB (non-CPB control animals). Lambs were prepared and monitored as for the $\mathrm{CPB}$ groups and maintained under anesthesia for 1 hour before cardiectomy. Cardiac standstill was achieved after a terminal dose of cardioplegia in 4 of the 7 control animals. Blood was obtained from the ewe for the purpose of making blood cardioplegia. The other 3 nonCPB control animals were killed with pentobarbitone, also during anesthesia with the sternum open, allowing rapid cardiectomy and specimen preservation. These 2 approaches were used to account for the effect of cardioplegia on myocardial water content because it is recognized that cardioplegia administration itself increases myocardial water content. ${ }^{9}$

CPB groups. Of the 9 lambs undergoing CPB, 3 underwent 90 minutes of bypass without $\mathrm{AXC}(\mathrm{CPB}-\mathrm{AXC})$ and were maintained for 3 hours after separation from bypass. The remaining 6 had AXC and were maintained for either $3(n=3)$ or $6(n=3)$ hours after separation from bypass. Lambs were chosen because of physiologic similarities to infant humans and because DNA sequences for AQPs are published for the sheep, unlike the pig.

Experimental preparation. Neonatal lambs were anesthetized by means of spontaneously breathing isoflurane and given intravenous ketamine $(1 \mathrm{mg} / \mathrm{kg})$ and midazolam $(100 \mu \mathrm{g} / \mathrm{kg})$. The lamb was intubated with a $5.5 \mathrm{~mm}$ cuffed endotracheal tube. Ventilation was maintained with a Campbell ventilator (ULCO, Marrickville, New South Wales, Australia), aiming for physiologically normal oxygen saturations (100\%) and $\mathrm{PaCO}_{2}$ values $(40-45 \mathrm{~mm} \mathrm{Hg}$ ); typical ventilation parameters were 20 to $25 \mathrm{~cm} \mathrm{H}_{2} \mathrm{O}$ on $5 \mathrm{~cm}$ 
$\mathrm{H}_{2} \mathrm{O}$ in $100 \%$ oxygen. General anesthesia was maintained with inhaled isoflurane $(0.1 \%-1 \%)$ continuously through the circuit, and intermittent ketamine, midazolam, and pancuronium were also administered as required. Intravenous flucloxacillin $(25 \mathrm{mg} / \mathrm{kg})$ was given every 6 hours. A 3-lumen, 4.5F, 13-cm central line (Arrow, Reading, $\mathrm{Pa}$ ) was placed percutaneously into the right internal jugular vein. A single lumen $(20-\mathrm{cm}, 3 \mathrm{~F}$ catheter; Cook, Bloomington, Ind) was inserted percutaneously into the right femoral artery. Cutaneous 3-lead electrocardiography, rectal temperature, central venous pressure, and intra-arterial pressure were monitored continuously. Venous and arterial blood gases were taken regularly.

CPB technique. Midline sternotomy was performed, and the pericardium was opened. CPB was established after heparin administration (400 IU/kg) with right atrial and ascending aortic cannulation. The extracorporeal circuit was established with a heart-lung machine (Cobe, Arvada, Colo). A standard $1 / 4-1 / 4-$ or $1 / 4-3 / 8-$ inch bypass circuit was used connected to a Terumo RX5 or SX10 oxygenator with an open venous reservoir and Terumo Capiox AF02 arterial filter (Terumo, Tokyo, Japan). About $90 \%$ of the bypass circuit prime volume was composed of maternal sheep blood and about $10 \%$ of Baxter Plasma Lyte-148-Replacement fluid (Baxter, Old Toongabbie, New South Wales, Australia) buffered with sodium bicarbonate and about 3 units of heparin per milliliter of prime fluid. Nonpulsatile flow rates were adjusted to maintain a flow rate of approximately $150 \mathrm{~mL} \cdot \mathrm{kg}^{-1} \cdot \mathrm{min}^{-1}$ and mean systemic pressures between 30 to $40 \mathrm{~mm} \mathrm{Hg}$. If necessary, the isoflurane dose was also varied to maintain the desired blood pressure range. The lambs' core temperatures were slowly decreased to $28^{\circ} \mathrm{C}$ to $30^{\circ} \mathrm{C}$ with a heater-cooler unit (Conair-Churchill, Pittsburgh, $\mathrm{Pa}$ ).

In the $\mathrm{CPB}+\mathrm{AXC}$ group, after establishment of $\mathrm{CPB}$, the aorta was crossclamped and blood cardioplegia at $4{ }^{\circ} \mathrm{C}$ was administered at $20 \mathrm{~mL} / \mathrm{kg}$ into the proximal ascending aorta. The cardioplegia comprised a 4:1 blood/crystalloid mix. This was delivered every 20 minutes into the aortic root for 90 minutes, at which point bypass was weaned and the native circulation was re-established. The average composition of the initial CPB machine prime, which did not significantly differ between treatment groups, was as follows: pH, 7.6; $\mathrm{PCO}_{2}, 24 \mathrm{~mm} \mathrm{Hg} ; \mathrm{PO}_{2}, 202 \mathrm{~mm} \mathrm{Hg}$; hematocrit, 21\%; K, $4.4 \mathrm{mmol} / \mathrm{L}$; Ca, $0.4 \mathrm{mmol} / \mathrm{L}$; and bicarbonate, $21 \mathrm{mmol} / \mathrm{L}$. Modified ultrafiltration was performed on all lambs undergoing CPB, and internal defibrillation $(0.5-1.0 \mathrm{~J} / \mathrm{kg})$, lignocaine $(1 \mathrm{mg} / \mathrm{kg})$, or both were administered as required. Routine surgical techniques in maintenance and weaning from CPB were used, including venting of the left atrial appendage in all cases.

Postoperative management. After the re-establishment of the native circulation, protamine (1-3 mg/kg) was administered, and hemostasis was achieved. The sternotomy was closed over two $28 \mathrm{~F}$ intrathoracic drains, which were placed on low-pressure wall suction. Dopamine (approximately $5 \mu \mathrm{g} \cdot \mathrm{kg}^{-1} \cdot \mathrm{min}^{-1}$ ) and sodium nitroprusside (approximately $1 \mu \mathrm{g} \cdot \mathrm{kg}^{-1} \cdot \mathrm{min}^{-1}$ ) were commenced after $\mathrm{CPB}$ and adjusted as required to maintain an adequate blood pressure (mean blood pressure, $>50 \mathrm{~mm} \mathrm{Hg}$ ), crystalloid or maternal blood was administered to maintain an adequate preload (central venous pressure, $>4 \mathrm{~mm} \mathrm{Hg})$, and hemoglobin $(>8 \mathrm{~g} / \mathrm{dL})$ and inhalational anesthesia were continued together with intermittent intravenous agents (ketamine and midazolam) and pancuronium. Ventilation was maintained and adjusted according to blood gas parameters. All animals were managed by a pediatric intensive care consultant (JRE) using conventional techniques relevant to the care of human infants.

Tissue collection. After either $3(n=6)$ or $6(n=3)$ hours of reperfusion after bypass, the sternotomy was reopened, the aorta was crossclamped, and a further dose of approximately $4{ }^{\circ} \mathrm{C}$ cardioplegia was delivered. After electrical and cardiac standstill for approximately 60 seconds, the heart was removed and placed on ice while dissected for further analysis. The heart was transversely sectioned into the atria, great vessels, and ventricles. The ventricles were sectioned for wet/dry weights and, together with other organ tissues, were either frozen at $-80^{\circ} \mathrm{C}$ or placed in $4 \%$ paraformaldehyde for sectioning.

\section{Tissue Analysis}

Myocardial water content. Samples of intraventricular septum and left and right free walls were weighed after blotting. They were then dried at approximately $80^{\circ} \mathrm{C}$ for 48 hours or until their weights were static. Myocardial water content was then calculated as $\{[$ Weight $($ wet $)-$ Weight $($ dry $)] /$ Weight $($ wet $)\}$ and expressed as a proportion.

Myocardial AQPs. Myocardial AQP1 mRNA and protein levels were quantified in ventricular myocardium by using techniques we have previously reported ${ }^{17}$ and elaborated on in Appendix E1.

Apoptosis. Assessment of apoptotic cell death was performed by using the TdT-mediated dUTP nick-end labeling (TUNEL) assay with the In Situ Cell Death Detection Kit (Roche, Basal, Switzerland). Positively labeled cells versus total cells were counted to quantify cell death. The entire slide was scanned at high-power magnification by an observer blinded to animal allocation (TLB). Hematoxylin and eosin-stained slides were also reviewed in a blinded fashion to review tissue integrity and exclude necrosis. Western blots for active caspase 3 were prepared by using cytoplasmic fractions.

\section{Statistical Analysis}

Data are expressed as means \pm standard error of the mean. Statistical significance was determined by using both the Mann-Whitney $U$ test and linear mixed models with covariance type AR-1. The statistical package SPSSv15.0 for Windows (SPSS, Inc, Chicago, Ill) was used for analysis. The animals receiving $\mathrm{CPB} \pm \mathrm{AXC}$ were compared in terms of hemodynamic variables, both functional and biochemical. Hemodynamic variables were analyzed over the complete survival period and also by means of comparison of 30-minute epochs. Our sample size gave us $80 \%$ power to demonstrate that a 2.3-standard-deviation effect size difference between groups was significant at a $P$ value of less than .05 . For measures of myocardial water content, AQP1 expression, and apoptosis, comparison was made between non-CPB control animals and animals receiving $\mathrm{CPB} \pm \mathrm{AXC}$.

\section{Results}

All experiments were completed as intended, and there were no significant differences in pre-CPB hemodynamic values. There were no inotropes or vasodilators administered before $\mathrm{CPB}$, and baseline biochemical indices, which were not significantly different, are shown in Table E1. The animals received similar weight-based doses of sedatives, analgesics, anesthetics, and muscle relaxants. 


\section{Hemodynamics}

The hemodynamic picture of LCOS was seen in those animals that underwent $\mathrm{CPB}+\mathrm{AXC}$ (Figure 1). The lambs undergoing $\mathrm{CPB}+\mathrm{AXC}$ were more hypotensive after $\mathrm{CPB}$. Mean blood pressure was significantly less, as determined by mixed model analysis $(P<.01$ after CPB). Diastolic blood pressure was also significantly less, as determined by using mixed-model analysis $(P<.05$ after $\mathrm{CPB})$. The differences remained at the end of the survival period. Systolic blood pressure was lower in the $\mathrm{CPB}+\mathrm{AXC}$ group, and this was significant by means of the Mann-Whitney $U$ test for the early and mid epochs after CPB. Heart rate was higher in the CPB + AXC group, also by means of the Mann-Whitney $U$ test, in all but the last post-CPB epoch. Central venous pressure, fluid requirements, and doses of vasoactive medications did not differ significantly between the groups.

\section{Biochemistry}

The CPB + AXC group had a higher lactate value (6.5 vs 3.6 $\mathrm{mmol} / \mathrm{L}, P<.05$ ) after CPB. However, by 3 hours after $\mathrm{CPB}$, the differences were not significant $(3.1 \mathrm{mmol} / \mathrm{L}$ in the $\mathrm{CPB}+\mathrm{AXC}$ group and $2.1 \mathrm{mmol} / \mathrm{L}$ in the $\mathrm{CPB}-\mathrm{AXC}$ group). The $\mathrm{CPB}+\mathrm{AXC}$ group had a persistently lower venous saturation after $\mathrm{CPB}$. The initial post-CPB venous saturation was $61 \%$ in the $\mathrm{CPB}+\mathrm{AXC}$ group compared with $76.7 \%(P<$ $.05)$ in the $\mathrm{CPB}-\mathrm{AXC}$ group. The venous saturations at 3 hours after $\mathrm{CPB}$ were $70 \%$ and $83.8 \%(P<.05)$, respectively (Figure 1). The glucose and hemoglobin levels remained similar in the $2 \mathrm{CPB}$ groups. The colloid osmotic pressure (COP) was not significantly different between the $2 \mathrm{CPB}$ groups at any time after $\mathrm{CPB}$. COP showed the expected increase after modified ultrafiltration. In the $\mathrm{CPB}-\mathrm{AXC}$ group it increased from $12.3 \mathrm{mOsm}$ to $14.5 \mathrm{mOsm}$, and in the $\mathrm{CPB}+\mathrm{AXC}$ group it increased from $13.5 \mathrm{mOsm}$ to $15.7 \mathrm{mOsm}$. After a further 3 hours, the COPs were 13 mOsm and 13.6 mOsm, respectively.

\section{Myocardial Water Content}

Myocardial water content was increased (not significantly) in the tissue from control lambs that were killed after terminal cardioplegia (0.785) as opposed to that seen in the control lambs that received pentobarbitone (0.781). Myocardial water content in the $\mathrm{CPB}-\mathrm{AXC}$ group was 0.787 , whereas in the $\mathrm{CPB}+\mathrm{AXC}$ group it was 0.796 , which was significantly greater than that seen in cardioplegia control tissue $(P<$ $.05)$. In summary, there was a $1 \%$ increase in myocardial water content associated with $\mathrm{CPB}+\mathrm{AXC}$, with only a $0.2 \%$ increase in myocardial water content in the $\mathrm{CPB}-\mathrm{AXC}$ group (Figure 2).

\section{Molecular Results}

Myocardial AQP1 mRNA levels, as determined by means of quantitative real-time polymerase chain reaction, were increased 2-fold in the $\mathrm{CPB}+\mathrm{AXC}$ group compared with those seen in control tissue $(P<.05)$. AQP1 mRNA levels in the $\mathrm{CPB}+\mathrm{AXC}$ group were also significantly higher when compared with those in the CPB-AXC group $(P<.05$, Figure 3$)$. There was no associated increase in AQP1 levels on Western blot analysis in either of the CPB groups (Figure 4). AQP4 transcript was not altered compared with that seen in control animals in either $\mathrm{CPB}$ group, and low protein levels were also unchanged by experimental group (data not shown). AQP0, AQP3, and AQP9 transcript was detectable at low levels. No appreciable changes were seen in these levels with quantitative real-time polymerase chain reaction (data not shown). Protein for these 3 AQPs was not demonstrable by means of Western blotting, despite appropriate antibodies and control tissue (data not shown).

\section{Apoptosis}

Completed apoptosis was not demonstrable by means of TUNEL staining in any of the preparations to a significant degree. Hematoxylin and eosin-stained slides also did not demonstrate necrosis, although tissue edema was more apparent in the $\mathrm{CPB}+\mathrm{AXC}$ group. Levels of caspase 3 protein, an early marker of apoptotic pathway induction, ${ }^{23}$ were significantly increased in the $\mathrm{CPB}+\mathrm{AXC}$ group. The control and $\mathrm{CPB}-$ AXC groups had comparable levels of caspase 3 (Figure 5).

\section{Discussion}

Clinical and laboratory features of LCOS were reproduced in a clinically accurate model in lambs that underwent $\mathrm{CPB}$ with myocardial I/R. These animals also had significant gains in myocardial water content and an increase in AQP1 transcript levels that has not been previously described. These data provide novel insights into the pathophysiology of capillary leak syndrome and myocardial edema in the setting of postoperative LCOS.

Hemodynamic changes consistent with LCOS were seen immediately after $\mathrm{CPB}$. In the $\mathrm{CPB}+\mathrm{AXC}$ animals there was significant tachycardia and systolic dysfunction. Impaired tissue oxygen delivery and lower diastolic pressure also occurred in those animals after $\mathrm{CPB}+\mathrm{AXC}$. CPB alone did not result in significant hemodynamic or biochemical derangements; it was $\mathrm{I} / \mathrm{R}$ that was primarily associated with hemodynamic dysfunction and impaired tissue oxygen delivery. The primacy of $\mathrm{I} / \mathrm{R}$ in precipitating LCOS has been alluded to previously; however, in some well-controlled animal experiments, this has not been demonstrated. ${ }^{24,25}$ In our series CPB alone was well tolerated, and it was only when coupled with $\mathrm{I} / \mathrm{R}$ that significant perturbations in circulatory function resulted. Consequently, measures to minimize the duration and effect of I/R should be the focus of ongoing research into LCOS.

The greatest degree of myocardial edema was seen in those animals after CPB with I/R. CPB without I/R was not associated with development of significant myocardial edema. These data prompt a re-evaluation of the dogma surrounding capillary leak and its contribution to the development of 

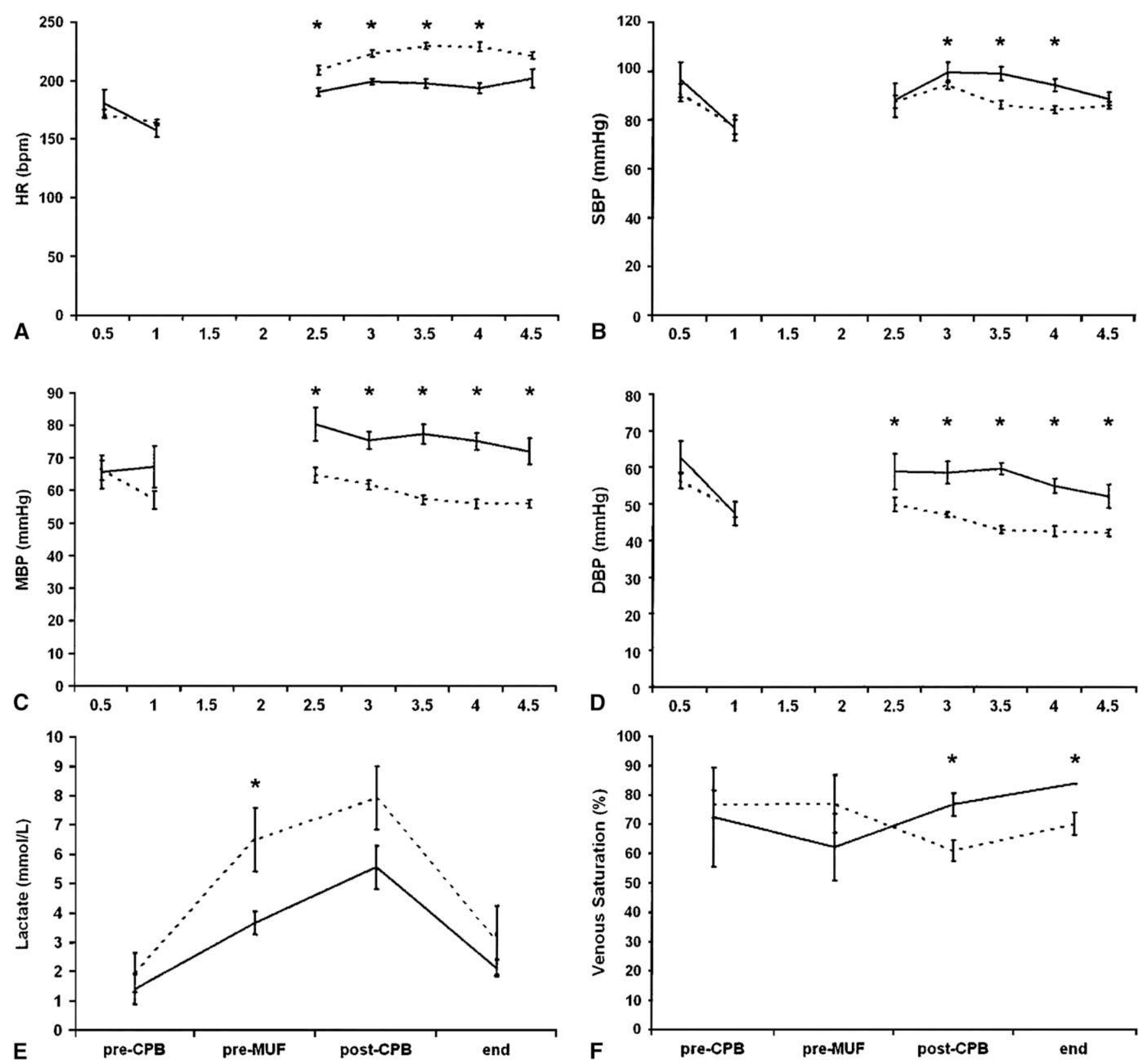

Figure 1. Hemodynamic and biochemical variables. In $A$ through $F$, lambs are grouped as undergoing cardiopulmonary bypass (CPB) without aortic crossclamping (AXC; solid line) and CPB with AXC (dashed line). A shows similar heart rates between groups, but after $C P B$, the $C P B+A X C$ group have a significantly higher heart rate until the last 30-minute epoch of postoperative analysis (Mann-Whitney $U$ test). B displays systolic blood pressure, which is significantly lower in the CPB + AXC group in the mid epochs after CPB (Mann-Whitney $U$ test). C and D show mean blood pressure and diastolic blood pressure, respectively, being significantly lower in the CPB + AXC group throughout the postoperative period (mixed-model analysis). E demonstrates a higher lactate level in the CPB + AXC group just before the completion of CPB (Mann-Whitney $U$ test). In $F$ there is a corresponding decrease in venous saturation in this group, which remains throughout the postoperative period (Mann-Whitney $U$ test). HR, Heart rate; $M B P$, mean blood pressure; $S B P$, systolic blood pressure; $D B P$, diastolic blood pressure. ${ }^{*} P<.05$. Data shown are presented as means \pm standard error of the mean.

myocardial edema after CPB. Ischemia is a potential confounder in several of the sentinel articles involved in asserting the link between edema and dysfunction, ${ }^{11,26}$ and there have been no previous attempts to experimentally differentiate the contribution of ischemia to edema-associated dysfunction. Edema does occur with CPB alone, and in our study it was 


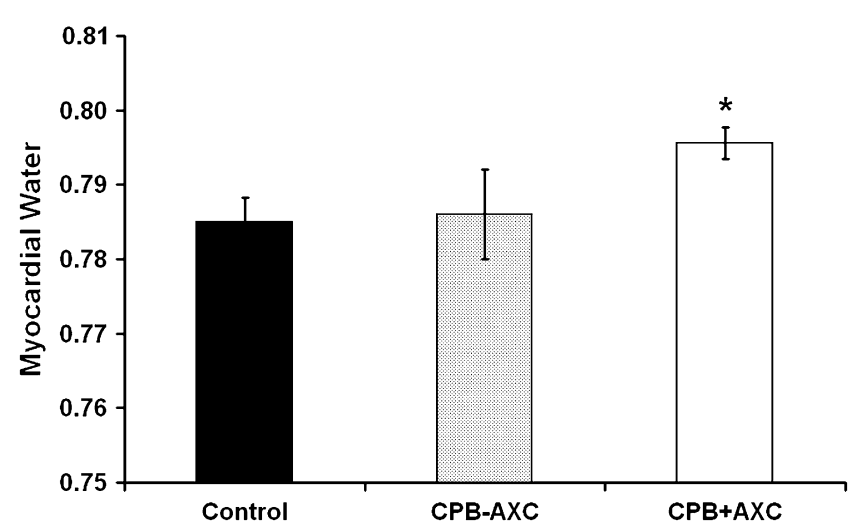

Figure 2. Myocardial water. Proportion of heart as water in noncardiopulmonary bypass (CPB) control animals (black column), lambs undergoing CPB without aortic crossclamping (AXC, gray column), and lambs undergoing CPB with AXC (white column). Significant myocardial edema was present in lambs undergoing CPB + AXC lambs, and a nonsignificant increase in myocardial water occurred in those undergoing CPB-AXC (Mann-Whitney $U$ test). ${ }^{*} P<.05$. Data shown are presented as means \pm standard error of the mean.

in the order of $0.2 \%$; this should not be and was not associated with significant myocardial dysfunction. It is likely that edema in this group was mainly interstitial or vasogenic in nature, resolved quickly, and was not associated with important dysfunction. Others have shown that such edema might have resolved within 6 hours. ${ }^{11}$ Hence it might have been possible

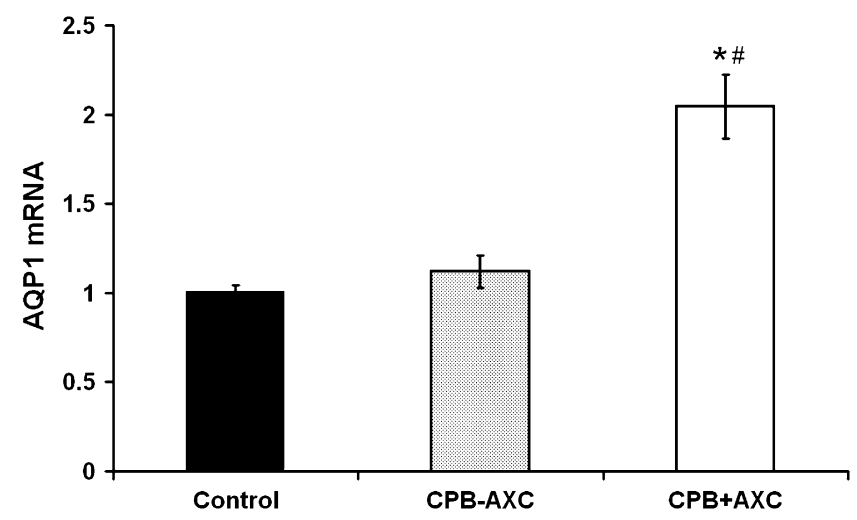

Figure 3. Myocardial aquaporin (AQP) 1 transcript expression. RNA was extracted from the myocardium of non-cardiopulmonary bypass (CPB) control animals (black column), lambs undergoing CPB without aortic crossclamping ( $A X C$, gray column), and lambs undergoing CPB + AXC (white column). The quantitative real-time polymerase chain reaction results shown are representative of at least 3 individuals in each group and are representative of 3 independent sets of experiments. AQP1 mRNA was normalized to ribosomal 18S RNA (Mann-Whitney $U$ test). ${ }^{*} P<.05$ versus non-CPB control animals and \#P<.05 versus the CPB-AXC group. Data shown are presented as means \pm standard error of the mean.

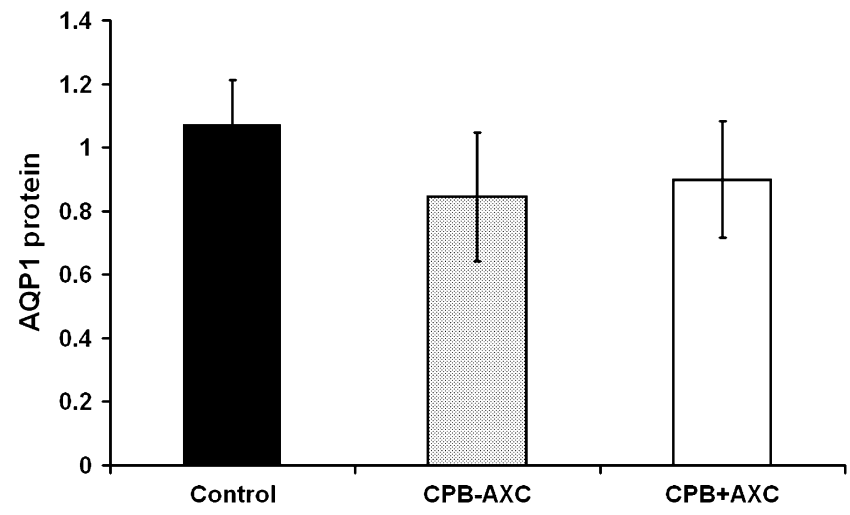

Figure 4. Myocardial aquaporin (AQP) 1 protein expression. AQP1 protein was obtained from the myocardium of non-cardiopulmonary bypass (CPB) control animals (black column), lambs undergoing CPB without aortic crossclamping ( $A X C$, gray column), and lambs undergoing CPB + AXC (white column). It was measured by Western blotting, analyzed by means of densitometry, and normalized to the expression of cardiac actin. Representative results demonstrate no significant differences between groups (MannWhitney $U$ test). ${ }^{*} P<.05$. Data shown are presented as means \pm standard error of the mean.

to demonstrate more myocardial edema after $\mathrm{CPB}$ alone if we had looked earlier in the postoperative period, but such a timeframe would not correlate with LCOS and dysfunction seen 6 to 12 hours postoperatively.

In our study ischemia was associated with a greater degree of edema formation and was associated with important dysfunction, as has been described by others. ${ }^{27}$ The $1 \%$ increase in myocardial water content that we observed after $\mathrm{I} / \mathrm{R}$ could be expected to result in possibly a $10 \%$ reduction in myocardial function based on the work of Laine and Allen. ${ }^{10} \mathrm{We}$ did not measure cardiac output or load-independent measures of myocardial function, but the average difference in mean blood pressure after CPB was $17 \mathrm{~mm}$ $\mathrm{Hg}(22 \%)$ when comparing those with or without $\mathrm{I} / \mathrm{R}$ in our study. This suggests that other factors, and not edema alone, are responsible. It is likely that $\mathrm{I} / \mathrm{R}$ results in a greater degree of interstitial or vasogenic edema that persists, as well as cytotoxic or intracellular edema caused by accumulation of lactate. Cytotoxic edema has been shown to be short lasting $^{28}$ but might reflect important effects on the contractile apparatus that persist for the duration of the LCOS, such as partial troponin I degradation. ${ }^{7}$

The increase in myocardial water content occurred without a significant reduction in COP. This is in keeping with other reports modeling the capillary leak syndrome after CPB. ${ }^{12,15}$ Hence there was movement of free water down osmotic gradients across the endothelium into the myocardial tissue. Water will move through AQPs, which exist abundantly within the endothelium and sarcolemma, to leak into the intracellular space of the myocardium if the osmotic 
Control
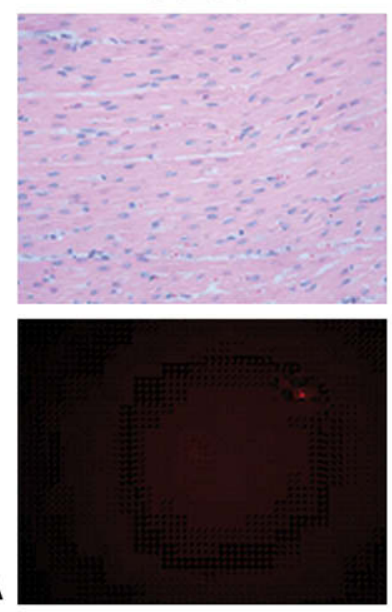

A
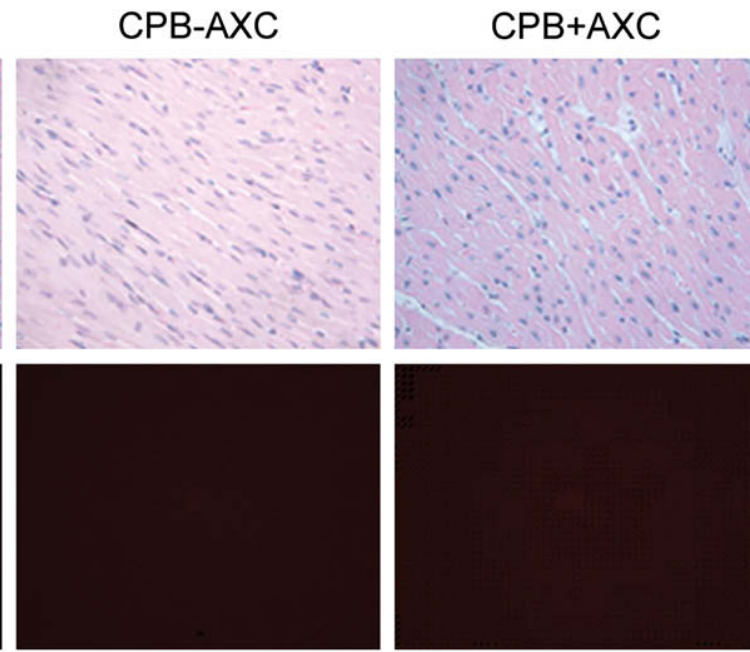

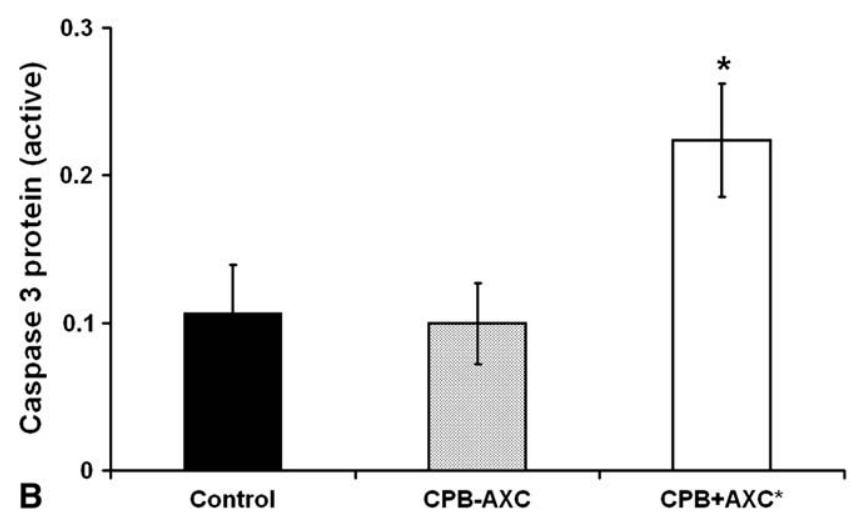

gradient mandates this, as can occur early during reperfusion as a result of intracellular lactate accumulation. ${ }^{16}$

AQP1 transcript was increased after CPB with ischemia within the myocardium. This increase was specific to those animals that had I/R and not CPB alone. This was a 2-fold increase in transcript but without an associated protein increase. AQP1 has been studied in a neonatal lamb heart previously in a deep hypothermic circulatory arrest model; no change in AQP1 expression was found in this study. ${ }^{21}$ Potentially, AQP1 expression might have been modified by inducing deep hypothermia, as has been described in other settings. ${ }^{29}$ Such modifications can affect edema formation and function, as reported elsewhere ${ }^{30}$; however, the effect of deep hypothermic circulatory arrest versus continuous flow on AQP expression was not the focus of our study.

The finding that AQP1 transcript increased in the lambs after $\mathrm{CPB}+\mathrm{AXC}$ differs from our earlier results with a rat isolated heart model. In the rat a brief period of global ischemia with reperfusion was not associated with changes in AQP1 transcript or protein levels. ${ }^{17}$ Species differences, duration of ischemia, and postischemic observation, as well as use of $\mathrm{CPB}$, might explain these differences. On the basis of our earlier work, we do not believe that species differences adequately explain this difference because the AQP expression profile of the sheep is similar to those of the rat and human subject. Duration of ischemia can be important because upregulation of AQP1 has been shown in interventions lasting days rather than minutes to hours. In a fetal sheep model anemia induced myocardial AQP1 increase over 5 days, suggesting that longer timeframes permitted adjustments in myocardial AQP1 protein levels. ${ }^{20}$ Because experiments of longer duration have permitted changes in AQP transcript to be uncovered, it is likely that 9- to 12-hour experiments would be required to determine protein changes. We cannot determine the significance of the demonstrated 2-fold increase in AQP1 transcript, and this finding warrants further study.

The suggestion by Calderone and associates ${ }^{22}$ that induction of apoptotic pathways can cause postischemic dysfunction, as well as later cell loss, is an intriguing hypothesis. We sought to corroborate these findings but did not demonstrate completed apoptosis as an important factor in LCOS over the early time period. We did, however, demonstrate increased expression of caspase 3 in the $\mathrm{CPB}+\mathrm{AXC}$ group, which is 
suggestive of early apoptotic activation. ${ }^{23}$ Mitochondrial function was not measured in our study. The negative predictive value of TUNEL is greater than its positive predictive value, especially because it can be positive during tissue regeneration and recovery. ${ }^{23} \mathrm{We}$ support the possibility that apoptosis can be a contributing factor to LCOS, and this might be particularly important in young infants having multiple operations with repetitive cell loss over time. Because ischemia is the likely proapoptotic trigger, the findings reinforce the importance of better management of the myocardium during ischemia.

This study was limited by its small size and the fact that it was conducted in animals. The animals also did not have structural heart disease and hence no preoperative volume or pressure loading. Measurements of vascular/ventricular coupling, as well as load-independent measurements of systolic and diastolic function, will be required in future experiments. The hemodynamic and functional monitoring used to support our findings is somewhat rudimentary but equivalent to techniques relied on in the clinical setting.

$\mathrm{I} / \mathrm{R}$ was associated with a significant degree of myocardial edema, clinically relevant dysfunction, and increased expression of AQP1. Edema formation is mostly related to ischemia and not bypass: our findings do not support a causal role for myocardial edema in the development of LCOS. Some benefit can be gained by manipulation of water flux, possibly by targeting AQP expression; however, the main focus in LCOS research should be the prevention of postischemic dysfunction rather than the systemic inflammatory response to bypass and generalized water accumulation. Analysis of AQP1 knockout mice with isolated cardiomyocytes and isolated hearts will further our understanding of the role of AQPs in myocardial water handling.

We thank Professor Jenny Peat, statistician, for her advice on study design and data analysis. Dr Sandra Cooper and Dr Nan Yang provided assistance with the molecular analysis and interpretation. John Dittmer, Dr Pramesh Kovoor, and Jim Pouliopoulos provided assistance with perfusion and monitoring equipment. Dr Susan Arbuckle and Aysen Yuksel provided histopathology assistance. Leanne Mills and Trish McGregor assisted with logistics.

\section{References}

1. Hoffman TM, Wernovsky G, Atz AM, Kulik TJ, Nelson DP, Chang AC, et al. Efficacy and safety of milrinone in preventing low cardiac output syndrome in infants and children after corrective surgery for congenital heart disease. Circulation. 2003;107:996-1002.

2. Stocker CF, Shekerdemian LS, Norgaard MA, Brizard CP, Mynard JP, Horton SB, et al. Mechanisms of a reduced cardiac output and the effects of milrinone and levosimendan in a model of infant cardiopulmonary bypass. Crit Care Med. 2007;35:252-9.

3. Tibballs J, Kawahira Y, Carter BG, Donath S, Brizard C, Wilkinson J. Outcomes of surgical treatment of infants with hypoplastic left heart syndrome: an institutional experience 1983-2004. J Paediatr Child Health. 2007;43:746-51.
4. Wernovsky G, Wypij D, Jonas RA, Mayer JE Jr, Hanley FL, Hickey PR, et al. Postoperative course and hemodynamic profile after the arterial switch operation in neonates and infants. A comparison of low-flow cardiopulmonary bypass and circulatory arrest. Circulation. 1995;92: 2226-35.

5. Hamada Y, Kawachi K, Tsunooka N, Nakamura Y, Takano S, Imagawa H. Capillary leakage in cardiac surgery with cardiopulmonary bypass. Asian Cardiovasc Thorac Ann. 2004;12:193-7.

6. Seghaye MC. The clinical implications of the systemic inflammatory reaction related to cardiac operations in children. Cardiol Young. 2003;13: 228-39.

7. Bolli R, Marban E. Molecular and cellular mechanisms of myocardial stunning. Physiol Rev. 1999;79:609-34.

8. Carlson RE, Aisen AM, Buda AJ. Effect of reduction in myocardial edema on myocardial blood flow and ventricular function after coronary reperfusion. Am J Physiol Heart Circ Physiol. 1992;262(suppl):H641-8.

9. Spotnitz HM. Effects of edema on systolic and diastolic function in vivo. J Cardiothorac Surg. 1995;10(suppl):454-9.

10. Laine GA, Allen SJ. Left ventricular myocardial edema. Lymph flow, interstitial fibrosis, and cardiac function. Circ Res. 1991;68:1713-21.

11. Mehlhorn U, Davis KL, Burke EJ, Adams D, Laine GA, Allen SJ. Impact of cardiopulmonary bypass and cardioplegic arrest on myocardial lymphatic function. Am J Physiol Heart Circ Physiol. 1995;268(suppl): H178-83.

12. Tassani P, Schad H, Schreiber C, Zaccaria F, Haas F, Mossinger H, et al. Extravasation of albumin after cardiopulmonary bypass in newborns. J Cardiothorac Vasc Anesth. 2007;21:174-8.

13. Kloner RA, Jennings RB. Consequences of brief ischemia: stunning, preconditioning, and their clinical implications: part 1. Circulation. 2001;104:2981-9.

14. Egan JR, Butler TL, Au CG, Tan Y-M, North KN, Winlaw DS. Myocardial water handling and the role of aquaporins. Biochim Biophys Acta. 2006; 1758:1043-52.

15. Farstad M, Heltne JK, Rynning SE, Onarheim H, Mongstad A, Eliassen F, et al. Can the use of methylprednisolone, vitamin C, or alpha-trinositol prevent cold-induced fluid extravasation during cardiopulmonary bypass in piglets? J Thorac Cardiovasc Surg. 2004;127:525-34.

16. Au CG, Cooper ST, Lo HP, Compton AG, Yang N, Wintour EM, et al. Expression of aquaporin 1 in human cardiac and skeletal muscle. $J$ Mol Cell Cardiol. 2004;36:655-62.

17. Butler TL, Au CG, Yang B, Egan JR, Tan YM, Hardeman EC, et al. Cardiac aquaporin expression in humans, rats, and mice. Am J Physiol Heart Circ Physiol. 2006;291:H705-13.

18. Manley GT, Fujimura M, Ma T, Noshita N, Filiz F, Bollen AW, et al. Aquaporin-4 deletion in mice reduces brain edema after acute water intoxication and ischemic stroke. Nat Med. 2000;6:159-63.

19. Ogura T, Matsuda H, Imanishi S, Shibamoto T. Sarcolemmal hydraulic conductivity of guinea-pig and rat ventricular myocytes. Cardiovasc Res. 2002;54:590-600.

20. Jonker SS, Davis LE, van der Bilt JDW, Hadder B, Hohimer AR, Giraud GD, et al. Anaemia stimulates aquaporin 1 expression in the fetal sheep heart. Exp Physiol. 2003;88:691-8.

21. Tabbutt S, Nelson DP, Tsai N, Miura T, Hickey PR, Mayer JE, et al. Induction of aquaporin-1 mRNA following cardiopulmonary bypass and reperfusion. Mol Med. 1997;3:600-9.

22. Caldarone CA, Barner EW, Wang L, Karimi M, Mascio CE, Hammel JM, et al. Apoptosis-related mitochondrial dysfunction in the early postoperative neonatal lamb heart. Ann Thorac Surg. 2004;78: 948-55.

23. Rodriguez M, Schaper J. Apoptosis: measurement and technical issues. J Mol Cell Cardiol. 2005;38:15-20.

24. Cox CS Jr, Sauer H, Allen SJ, Laine GA. Myocardial performance after cardiopulmonary bypass and cardioplegic arrest: impact of na $+/ \mathrm{h}+$ exchanger inhibition. J Invest Surg. 2002;15:219-26.

25. Blatchford JW 3rd, Barragry TP, Lillehei TJ, Ring WS. Effects of cardioplegic arrest on left ventricular systolic and diastolic function of the intact neonatal heart. J Thorac Cardiovasc Surg. 1994;107:527-35.

26. Mehlhorn U, Allen SJ, Adams DL, Davis KL, Gogola GR, de Vivie ER, et al. Normothermic continuous antegrade blood cardioplegia does not prevent myocardial edema and cardiac dysfunction. Circulation. 1995; 92:1940-6. 
27. Palmer BS, Hadziahmetovic M, Veci T, Angelos MG. Global ischemic duration and reperfusion function in the isolated perfused rat heart. Resuscitation. 2004;62:97-106.

28. Askenasy N. Is cytotoxic cellular edema real? The effect of calcium ion on water homeostasis in the rat heart. Cardiovasc Toxicol. 2001;1:21-34.

29. Fujita Y, Yamamoto N, Sobue K, Inagaki M, Ito H, Arima H, et al. Effect of mild hypothermia on the expression of aquaporin family in cultured rat astrocytes under hypoxic condition. Neurosci Res. 2003; 47:437-44.

30. Tassani P, Barankay A, Haas F, Paek SU, Heilmaier M, Hess J, et al. Cardiac surgery with deep hypothermic circulatory arrest produces less systemic inflammatory response than low-flow cardiopulmonary bypass in newborns. J Thorac Cardiovasc Surg. 2002;123: 648-54.

Access to The Journal of Thoracic and Cardiovascular Surgery Online is reserved for print subscribers!

Full-text access to The Journal of Thoracic and Cardiovascular Surgery Online is available for all print subscribers. To activate your individual online subscription, please visit The Journal of Thoracic and Cardiovascular Surgery Online, point your browser to http://www.mosby.com/jtcvs, follow the prompts to activate your online access, and follow the instructions. To activate your account, you will need your subscriber account number, which you can find on your mailing label (note: the number of digits in your subscriber account number varies from 6 to 10). See the example below in which the subscriber account number has been circled:

\section{Sample mailing label}

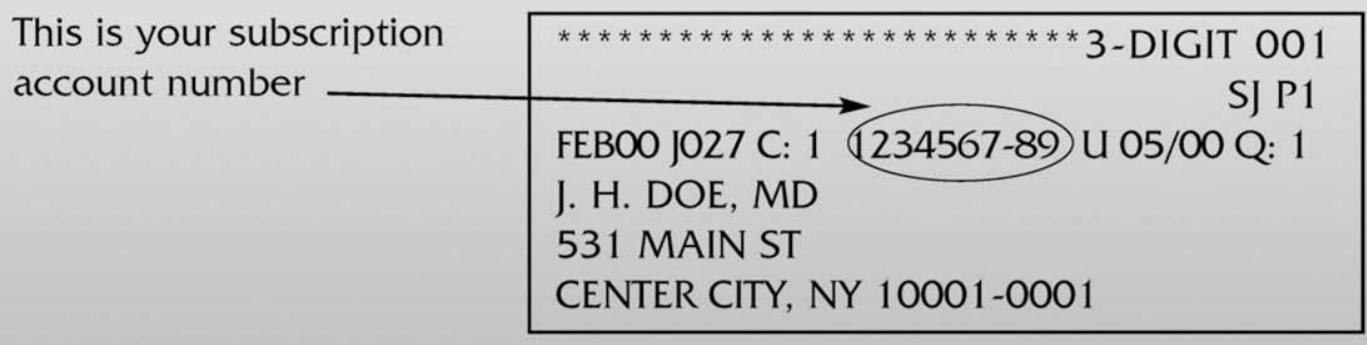

Personal subscriptions to The Journal of Thoracic and Cardiovascular Surgery Online are for individual use only and may not be transferred. Use of The Journal of Thoracic and Cardiovascular Surgery Online is subject to agreement to the terms and conditions as indicated online. 


\section{Appendix E1. Myocardial AQP1 mRNA and protein analysis}

Protein for Western blot analysis was prepared by using whole-cell lysates from frozen tissue. Total RNA was extracted from tissues by using Tri Reagent (Molecular Research Center, Cincinnati, Ohio), followed by cDNA synthesis with oligo dT and reverse transcriptase (Superscript III; Invitrogen, Carlsbad, Calif). Quantitative reverse transcriptase-polymerase chain reaction was performed with LUX primers (Invitrogen) for sheep AQP1 (5'-CGAGATCG CCACTGTCATCCTCT[FAM]G-3'; 5'-CATTGAGGCCA AGCGAGTTG-3'), AQP4 (5'-GACAGAAGAAAAGC
CATTACCTGT[FAM]G-3'; 5'-GATGCTGAGTCCAAAG CAGAGG- $\left.3^{\prime}\right)$, and $18 \mathrm{~S}$ ( $5^{\prime}$-GACCTGCCGAGATTGAG CAATAACAGG[FAM]C-3'; 5'-GTAGGGTAGGCACA CGCTGAG-3') by using the Platinum PCR SuperMixUDG kit (Invitrogen). All samples were run in duplicate. AQP levels were quantified during 45 cycles by using a Rotor-Gene RG 3000A (Corbett Research, Mortlake, New South Wales, Australia), and analysis was performed with Rotor-Gene Real Time Analysis Version 6.0 (Corbett Research). mRNA levels were quantified by using $18 \mathrm{~S}$ rRNA to normalize the raw AQP signal. 
TABLE E1. Baseline biochemical variables

Pre-CPB indices (mean \pm SEM)

\begin{tabular}{|c|c|c|c|c|c|c|}
\hline & \multirow[b]{2}{*}{$\mathbf{n}$} & & & & & \\
\hline & & Hemoglobin (g/dL) & Glucose (mmol/L) & Lactate (mmol/L) & Venous Saturation (\%) & COP (m0sm) \\
\hline Control & 4 & $10.5 \pm 0.8$ & $6.5 \pm 1.0$ & $1.5 \pm 0.3$ & $78 \pm 14.9$ & $13.8 \pm 1.3$ \\
\hline CPB-AXC & 3 & $10.3 \pm 0.2$ & $5.8 \pm 2.3$ & $1.4 \pm 0.5$ & $72.5 \pm 16.9$ & $12.3 \pm 1.5$ \\
\hline $\mathrm{CPB}+\mathrm{AXC}$ & 6 & $10.2 \pm 0.4$ & $5.7 \pm 0.4$ & $2 \pm 0.7$ & $76.8 \pm 4.7$ & $14.6 \pm 0.5$ \\
\hline
\end{tabular}

$C P B$, Cardiopulmonary bypass; $S E M$, standard error of the mean; $C O P$, colloid osmotic pressure; $A X C$, aortic crossclamp. 